\title{
Validation of Lumped Mass Lateral Cantilever Shaft Vibration Simulation on Fixed-Pitch Vertical-Axis Ocean Current Turbine
}

\author{
R. Hantoro ${ }^{1}$, I. K. A. P. Utama ${ }^{2}$, A. Sulisetyono ${ }^{2}$, and Erwandi $^{3}$
}

\begin{abstract}
Research on the emergence of force fluctuations and shaft vibration responses of ocean currents turbine generator become a serious concern to the researchers. This paper was conducted with the aim of investigation into the characteristics of lateral shaft vibration of a fixed-pitch vertical-axis ocean current turbine (VAOCT). The work was carried out numerically and experimentally using tank test. A cantilever type of shaft has been used and modeled using finite element method, and simulated using lumped mass matrix to obtain the vibration characteristics and responses. Variations of incoming fluid velocity and the corresponding rotation velocity (rpm) of VAOCT were used to identify the pattern of lateral displacement responses. Analysis of displacement responses at all nodes in $x$ and $y$-direction at the same time was carried out. The presents of displacement shapes recognized have close agreement to the $1^{\text {st }}$ mode shape. Potential problems on the tip of shaft obviously due to half of the force of turbine received concentrated at cantilever tip. The pattern of vibration responses from the test data shows suitable with simulation. Periodic pattern responses resulted from simulation and experiment at the validated node produce the minimum displacement error of $14 \%$ at $\operatorname{Var}-3(\mathrm{U}=1 \mathrm{~m} / \mathrm{s})$ and maximum of $24 \%$ at $\operatorname{Var}-2$ (U=0.9 $\mathbf{m} / \mathbf{s})$.
\end{abstract}

Keywords - Cantilever, finite-element, lumped-mass, lateral vibration, fixed-pitch, vertical-axis turbine

\section{INTRODUCTION}

$\mathrm{R}$ esearch on the effect of fluctuations of the force on the output power generated by energy conversion system from renewable energy sources (wind, ocean currents) has become a serious concern among researchers $[1,2]$. In the case of ocean current turbine system, the force of the fluid causes structure to rotate and change its orientation to the incoming fluid flow. Force fluctuations which follow the turbine during rotation was strongly influenced by foil's position to the incoming flow and become potency of vibrations on the turbine shaft. The use of fixed-pitch not allowed foil to change its relative position to the arm.

This paper discussed the characteristics of lateral vibration on the main shaft of vertical-axis ocean current turbine with the use of fixed-pitch blade. A cantilever type of shaft was used and modeled using finite element method. Simulation was carried out using lumped mass matrix in the Matlab package to obtain the natural

${ }^{1} \mathrm{R}$. Hantoro is Student of Naval Architecture and Shipbuilding Engineering Doctorate Program, FTK, Institut Teknologi Sepuluh Nopember, Surabaya, 60111, Indonesia. E-mail: hantoro@ep.its.ac.id.

${ }^{2}$ I. K. A. P Utama, A. Sulisetyono, and Erwandi are with Departement of Naval Architecture and Shipbuilding Engineering, FTK, Institut Teknologi Sepuluh Nopember, Surabaya, 60111, Indonesia. frequencies, mode shapes and deflection of vibration response. Fourier force function used in the simulation was taken from force fluctuations data obtained at previous CFD simulation by Hantoro, et al [3, 4]. Experiment was conducted as validation of the simulation results at a node of the finite element model.

\section{THEORIES AND LITERATURE REVIEW}

For dynamic response analysis, a linearized finite element model was employed to establish a control scheme for rotor systems [5]. The finite element method was also applied to a complex rotor system to evaluate its vibration response due to fluid forces [6], and gyroscopic moments [7]. Although early dynamic models of rotor systems were formulated either analytically [8] or using transfer matrix approach [9], the potential of the powerful finite element technique was recognized at a very early stage [10]. In general, a structure is analyzed as a system of continuous or discrete systems (lumped system). A uniform structures like rod can be more appropriate if treated as a continuous system. Finite element method in fact can be called a combination of two methods, namely the continuous and discrete elements in the level of general coordinates.

In this study, the vertical axis turbine is modeled as a system consisting of the shaft which is divided into 10 elements. Three foils as producer of excitation force rests at two points on the shaft (node-3 and node-10), as shown in Fig. 1. With the total length of $1400 \mathrm{~mm}$, each element has length of $140 \mathrm{~mm}$. Magnetic probe sensor (eddy currents) is placed at node- 1 in the $\mathrm{x}$ and $\mathrm{y}$ direction with a distance of $140 \mathrm{~mm}$ from the bearing (node-1) in order to obtain displacement data. Parameters of flexible cantilever shaft turbine with specified stiffness used in simulation and experiment are:

TABLE 1.

MATERIAL SPECIFICATIONS

$\begin{array}{lll}\text { - shaft material } & : & \text { SS304 } \\ \text { - modulus elasticity }(\mathrm{E}) & : & 200 \mathrm{GPa} \\ \text { - shear modulus }(\mathrm{G}) & : & 86 \mathrm{GPa} \\ \text { - shaft dimension } & : & \text { Length } 1400 \mathrm{~mm}, \\ & & \text { diameter } 44.5 \mathrm{~mm} \\ \text { - density } & : & 8000 \mathrm{~kg} / \mathrm{m}^{3}\end{array}$

The element stiffness matrix can be developed using basic strength of materials techniques to analyze the forces required to displace each degree of freedom a unit value in the positive direction. Using the degrees of freedom of element stiffness matrix results in the following element stiffness matrix:

The element stiffness matrix can be developed using basic strength of materials techniques to analyze the 
forces required to displace each degree of freedom a unit value in the positive direction. Using the degrees of freedom of element stiffness matrix results in the following element stiffness matrix:

$$
\mathrm{K}_{\mathrm{e}, \mathrm{i}}=\mathrm{E}_{\mathrm{i}} \mathrm{I}_{\mathrm{i}}\left[\begin{array}{cccc}
\frac{12}{\mathrm{l}_{\mathrm{i}}^{3}} & \frac{6}{\mathrm{l}_{\mathrm{i}}^{2}} & \frac{-12}{\mathrm{l}_{\mathrm{i}}^{3}} & \frac{6}{\mathrm{l}_{\mathrm{i}}^{2}} \\
\frac{6}{\mathrm{l}_{\mathrm{i}}^{2}} & \frac{4}{\mathrm{l}_{\mathrm{i}}} & \frac{-6}{\mathrm{l}_{\mathrm{i}}^{2}} & \frac{2}{\mathrm{l}_{\mathrm{i}}} \\
\frac{-12}{\mathrm{l}_{\mathrm{i}}^{3}} & \frac{-6}{\mathrm{l}_{\mathrm{i}}^{2}} & \frac{12}{\mathrm{l}_{\mathrm{i}}^{3}} & \frac{-6}{\mathrm{l}_{\mathrm{i}}^{2}} \\
\frac{6}{\mathrm{l}_{\mathrm{i}}^{2}} & \frac{2}{\mathrm{l}_{\mathrm{i}}} & \frac{-6}{\mathrm{l}_{\mathrm{i}}^{2}} & \frac{4}{\mathrm{l}_{\mathrm{i}}}
\end{array}\right]
$$

For cantilever beam with two element model with one end not allowed to move, it is necessary to eliminate the degree of freedom. Elimination made to the rows and columns which correspond to the constrained global degrees of freedom, reducing the global stiffness matrix to a $4 \times 4$ matrix, resulting as in Equation (2).

$$
K_{g}=\left[\begin{array}{cccc}
\left(\frac{12 E_{1} I_{1}}{l_{i}^{3}}+\frac{12 E_{2} I_{2}}{l_{i}^{3}}\right) & \left(\frac{-6 E_{1} I_{1}}{l_{i}^{2}}+\frac{6 E_{2} I_{2}}{l_{i}^{2}}\right) & \frac{-12 E_{2} I_{2}}{l_{2}^{3}} & \frac{6 E_{2} I_{2}}{l_{i}^{2}} \\
\left(\frac{-6 E_{1} I_{2}}{l_{1}^{2}}+\frac{6 E_{2} I_{2}}{l_{2}^{2}}\right) & \left(\frac{4 E_{1} I_{1}}{l_{1}^{2}}+\frac{4 E_{2} I_{2}}{l_{2}^{2}}\right) & \frac{-6 E_{2} I_{2}}{l_{2}^{2}} & \frac{2 E_{2} I_{2}}{l_{2}} \\
\frac{-12 E_{2} I_{2}}{l_{2}^{3}} & \frac{-6 E_{2} I_{2}}{l_{2}^{2}} & \frac{12 E_{2} I_{2}}{l_{2}^{3}} & \frac{-6 E_{2} I_{2}}{l_{2}^{2}} \\
\frac{6 E_{2} I_{2}}{l_{2}^{2}} & \frac{2 E_{2} I_{2}}{l_{2}^{2}} & \frac{-6 E_{2} I_{2}}{l_{2}^{2}} & \frac{4 E_{2} I_{2}}{l_{2}}
\end{array}\right]
$$

The same method can be performed on the number of element more than two with considering of the computing capability to perform high order matrix operations. For a beam which is modeled with finite element method there are several method to form the mass matrix, namely: (a) lumped mass for the translation, (b) lumped mass for the translation and rotation, and (c) consistent mass distributed mass effects. The parameters of mass and inertial mass matrix element connecting rods in the inertial load point to point and given the acceleration in the diagonal matrix. Equation (3) shows the lumped mass matrix (LM), including translation and rotation,

$$
\mathrm{m}_{\mathrm{g}}=\left[\begin{array}{cccc}
\left(\frac{\mathrm{ml}}{2}\right) & 0 & 0 & 0 \\
0 & \left(\frac{\mathrm{ml}^{3}}{24}+\frac{\mathrm{mlI}_{\mathrm{y}}}{2 \mathrm{~A}}\right) & 0 & 0 \\
0 & 0 & \left(\frac{\mathrm{ml}}{2}\right) & 0 \\
0 & 0 & 0 & \left(\frac{\mathrm{ml}^{3}}{24}+\frac{\mathrm{mlI}_{\mathrm{y}}}{2 \mathrm{~A}}\right)
\end{array}\right]
$$

With the acquisition of $\mathbf{m}_{\mathrm{g}}$ and $\mathbf{k}_{\mathrm{g}}$ then the eigenvalue problem for homogeneous equations of motion can be writen,

$m_{g} \ddot{z}+k_{g} z=[0]$

Fourier-force function are used to obtain the vibration response with respect to time and the external forces acting on the shaft. It is obtained by making Equation (4) becomes,

$\left[m_{g} k_{g}\right][\bar{z}]=[\bar{F}]$

and all nodes in the deviation of $\mathrm{z}$ is,

$[\bar{z}]=\left[m_{g} k_{g}\right]^{-1}[\bar{F}]$

CFD simulation performed on previous research by Hantoro et al. [4] have resulted the pattern of force fluctuations in variations of flow velocity and rotation speed of turbine. Limited variations due to carriage capability that are performed in this study are shown in Table 2. The increment of incoming fluid velocity (U) and rotation velocity (rpm) is compared and shows a linear correlation.
TABLE 2.

\begin{tabular}{ccc}
\multicolumn{3}{c}{ TOWING TANK VARIATIONS TEST } \\
\hline Variation & $\mathrm{U}(\mathrm{m} / \mathrm{s})$ & RPM \\
\hline Var-1 & 0.8 & 37 \\
Var-2 & 0.9 & 39 \\
Var-3 & 1 & 42
\end{tabular}

Force fluctuation patterns appear in a full rotation at all variations classified in two directions as defined in Fig. 2. Simulation of lateral vibration on the main shaft for every variation was performed in two directions, namely in $\mathrm{x}$ and $\mathrm{y}$-direction. Force in $\mathrm{x}$-direction is the force acting on a rotating turbine in the same direction with the incoming fluid flow, while the y-direction is for the force that is perpendicular to the incoming fluid flow.

The resulted force fluctuations of turbine for all variations which are acting on the shaft provides periodic pattern as shown in Fig. 3.

The use of fixed pitch foil on turbine results periodic fluctuation pattern in $F_{x}$ and $F_{y}$, with three periods in a full rotation. A period of fluctuation occurred at the position of azimuth $(\theta)$ in $120^{\circ}$ interval. The number of foils used in this study were three foil and give the distances between them of $120^{\circ}$. Therefore, it can be concluded that the periodicity of fluctuation pattern in a vertical axis turbine is correlated to the distance between the foils used.

Fourier force function modeling performed by taking a period $(T)$ of fluctuation patterns, coefficients $a_{0}, a_{n}$, and $b_{n}$ were obtained with the equation :

$a_{0}=\frac{1}{T} \int_{-T / 2}^{T / 2} z(t) d t$

$a_{n}=\frac{2}{T} \int_{-T / 2}^{T / 2} x(t) \cos n \omega_{0} t . d t$

$b_{n}=\frac{2}{T} \int_{-T / 2}^{T / 2} x(t) \sin n \omega_{0} t . d t$

$(\mathrm{n}=1,2,3, \ldots)$.

The coefficient of $a_{0}, a_{n}$, and $b_{n}$ produced by performing $\mathrm{n}$ iterations to obtain the sum of sine and cosine functions in accordance with the pattern of force fluctuation. Rearrange these coefficients resulting Fourier equation functions of the force versus time in the form of,

$z(t)=a_{0}+a_{1} \cos \omega_{0} t+a_{2} \cos 2 \omega_{0} t+a_{3} \cos 3 \omega_{0} t+\ldots$

$b_{1} \sin \omega_{0} t+b_{2} \sin 2 \omega_{0} t+b_{3} \sin 3 \omega_{0} t \ldots$

Results of modeling achieve agreement to fit after the $6^{\text {th }}$ order iterations. Plots of Fourier force function fluctuations performed with Matlab provides good agreement compared with the results of force fluctuation from CFD data simulation. Fig. 4 shows an example of the suitability at Var-2 variation.

The natural frequency $\left(\boldsymbol{\omega}_{\mathbf{n}}\right)$ was obtained by solving the roots of the determinant of the equations of motion using,

$\left[m_{g} k_{g}\right][z]=[0]$

$\omega_{n}=\operatorname{det}\left[m_{g} k_{g}\right]$

Coupling between elements gives the degrees of freedom two times the number of elements, resulting 20 varieties of natural frequency as shown in Fig. 5 and Table 3.The first three of 20 mode shapes that occurred is shown in Fig. 6. 
Modes are associated with structural resonances. The majority of structures can be made to resonate. That is, under the proper conditions, a structure can be made to vibrate with excessive, sustained motion. Resonant vibration is caused by an interaction between the inertial and elastic properties of the materials within a structure. Furthermore, resonant vibration is the cause of, or at least a contributing factor to, many of the vibration related problems that occur in structures and operating turbine.

In eigen problems of finite element analysis, both stiffness and mass matrices are, in fact, functions of natural frequencies. In the analysis, however, the natural frequencies are not known a priori. Hence, the static stiffness and mass matrices are employed to obtain the natural frequencies, which can be good approximations for the lowest modes.

Usually, the highest frequencies are considered to be less important in finite element dynamic analysis. Firstly, it is difficult, using the finite element method, to calculate the exact values in a continuous structural system which has an infinite number of degrees of freedom. Secondly, the highest frequencies may not have any practical meaning in large finite element systems when the real structures do not vibrate with those high frequencies.

In bending vibrations, higher modes have many points of zero displacement which are called nodes. As the number of nodes increases with each mode, severe wrinkling can occur in the vibration mode shape. Hence, for the highest modes, the effect of shear deformation and rotation may not be neglected and the simplified theory of beam bending is no longer valid.

\section{METHOD}

Experiments included the manufacture and testing of the work piece was carried out at the towing tank facility at Hydrodynamics Laboratory, Faculty of Marine Technology ITS, with specifications:

1. Length $50 \mathrm{~m}$,

2. Width $3 \mathrm{~m}$,

3. Depth $2 \mathrm{~m}$.

The foil chord was set at 100 millimetres, with span of $1000 \mathrm{~mm}$ giving aspect ratio of 10 , and $500 \mathrm{~mm}$ arm to the shaft. The turbine was designed with three foils. The NACA 0018 profile was chosen as the foil section with data from Sheldahl and Klimas [11]. This section is commonly used for Darrieus turbines. Its relatively high thickness to chord ratio gives it good strength in bending. The radial arms of the turbine were made from high strength aluminium. Turbine shaft using cantilever type with one end fixed by the bearing and the other end free (overhanging) as shown in Fig. 6.

Data collection was conducted with the same variation as mention in Table 1. The use of fixed-pitch was not allowed foil to change itsrelative position to the arm, as shown in Fig. 9.

Magnetic probe sensor (eddy currents) is placed at node- 1 in the $\mathrm{x}$ and $\mathrm{y}$-direction with a distance of 140 $\mathrm{mm}$ from the bearing in order to obtain displacement data (Fig. 10). Data collection was performed after towing tank carriage speed has stable with time sampling of 0.01 second.
Data collecting during test performed during the turbine move along the carriage. Displacement data of turbine shaft vibration taken at the position corresponding to the location of the node- 1 infinite element modeling.

Displacement of shaft for on erotation of the measured data in $\mathrm{x}$ and $\mathrm{y}$-direction was obtained in time domain $(\mathrm{t})$. Data for on rotation is provided by synchronization and matching time of the carriage velocity chart in the control room, time of video recorded, and the timeof displacement data which recorded in data logger.

\section{RESULTS AND DISCUSSION}

Resulted displacement from simulation at all nodes at the same time indicating the possibility of mode shape occurance. Fig.11 and Fig. 12 shows sample the displacement resulted at all nodes in $\mathrm{x}$ and $\mathrm{y}$-direction for all variations at $t_{i=1}, t_{i=10}, t_{i=30}$. Similar mode of displacement at all node was presented for all variations in $x$ and $y$-direction, and these modes recognized have close agreement to the $1^{\text {th }}$ mode shape resulted from simulation (Fig. 6.(a)).

Changes in inter-elements in the node- 9 to give significant difference when compared to the other nodes (Fig. 11 and Fig. 12). This indicates that the use of the cantilever shaft for vertical-axis ocean current turbine gives potential problems on the tip of shaft. It is obvious due to half of the force received on turbine concentrated at cantilever tip.

Vibration response generated in the simulation and testing in all variations and directions gives a periodic pattern follows the force pattern on the turbine shaft (Fig. 13, Fig. 14, and Fig. 15). Displacement resulted at node1 from the test provide lower values compared with simulation.

Responses of displacement appears in X-directionare consistent inpositive value. According to the definition of the direction of displacement which has been described previously, the position displacement is always in the region of $\mathrm{x}+$. Displacement at this area generated by the excitation force resulted form interaction between the incoming fluid and foils according to the position at the azimuth as the turbine rotates. This indicates that turbine shaft always experience lateral bending along its rotation.

Different direction of vibration response in y-direction showing strong influence of lift force generated by fixedpitch foil as force producer for vertical-axis ocean current turbine. Real displacement obtained using simple Pythagoras formula for displacement in $\mathrm{x}$ and $\mathrm{y}$ direction. The average error between the simulation and measurement at each of variation are given in Table 4.

Lumped mass matrix is a method by which dynamic coupling that appears in various degrees of freedom between the elements are not considered. However, since the mass matrix has the form of diagonal lumped, the computing time required in the shorter term. Moreover, it is well known that lumped mass matrices over estimate the mass effect and hence give higher value of vibration response than the exact ones. 


\section{CONCLUSIONS}

Simulation and testing of lateral shaft vibration of fixed-pitch vertical-axis ocean current turbine has been performed. Finite element method and lumped mass matrix was used to perform vibration respond. The present of similar mode of response displacement at all node recognizedhave close agreement to the $1^{\text {st }}$ mode shape resulted from simulation. Resulted displacement from simulation at all nodes in the same time indicating the present of critical part at node- 9 .

Turbine shaft always experience lateral bending along its rotation and strongly affected by the excitation force resulted form interaction between the incoming fluid and foils to the azimuth position. Potential problems on the tip of shaft obviously due to half of the force of turbine received concentrated at cantilever tip.

The use of eddy currents sensor for displacement measurement has given consistent response pattern compared to simulation results with the maximum displacement error of $24 \%$ at $\operatorname{Var}-2(\mathrm{U}=0.9 \mathrm{~m} / \mathrm{s})$ and the minimum of $17 \%$ at $\operatorname{Var}-3(\mathrm{U}=1 \mathrm{~m} / \mathrm{s})$ in $\mathrm{x}$ and $\mathrm{y}$ direction.

Displacementtest data at node-1 shows discretized pattern, i.e sensor reading in the form of magnetic induction in the interval range of $0.001 \mathrm{~mm}$. This resulted in the polarization of displacement values generated. When the induction was slightly above or below one of the intervals above the limit, the excess or lack of value will be truncated.

\section{ACKNOWLEDGEMENT}

1. The authors expressed their gratitude to DP2M Dikti and LPPM ITS for funding the research under research scheme known as Postgraduate Research Grand (HPTP) of the year 2009 and 2010.

2. The authors also thanks to technicians at the ITS towing tank for their helps in the experimental work.

\section{REFERENCES}

[1] P. L. Fraenkle, 2007, "Marine current turbines: pioneering the developmnet of marine kinetic energy converters", Proceedings of the Institution of Mechanical Engineers; 221, A2, ProQuest Science Journals pp. 159.

[2] C. R. Robert, H. W. Mark, 1978, "Torque ripple in a vertical axis wind turbine, Sandia Report SAND78-0577 1 Unlimited Release • UC-60", Printed April.

[3] Y. Kyozuka, 2008, "An experimental study on the DarieusSavonius Turbine for Tidal Current Power Generation", Journal of Fluid Science and Technology. Vol. 3, No. 3.

[4] R. Hantoro, I. K. A. P. Utama, Erwandi, 2009, "Unsteady Load Analysis on a Vertical Axis Ocean Current Turbine", The $11^{\text {th }}$ International Conference On QIR (Quality In Research), 3-6 August 2009, Indonesia University.

[5] R. Hantor, I. K. A. P. Utama, Erwandi , A. Sulisetyono, 2009, "Unsteady load and fluid-structure interaction of verical-axis ocean current turbine", Journal of Mechanical Engineering , Petra University Surabaya, Vol.11, No.1, April 2009, ISSN 1410-9867.

[6] S. C. Hsieh, J. H. Chen, dan A. C. Lee, 2008, "A Modified Transfer Matrix Method for Coupled Lateral and Torsional Vibrations of Asymetric Rotor Bearing Systems", Journal of Sound and Vibration, vol. 312, pp. 53-571.

[7] W. Diewald and R. Nordmann, 1989, "Dynamic analysis of centrifugal pump rotors with fluid-mechanical interactions", ASME Journal of Vibration and Acoustics, Stress, and Reliability in Design 111, pp. 370-378.

[8] M. Sakata, K. Kimura, S. K. Park and H. Ohnabe, 1989, "Vibration of bladed flexible rotor due to gyroscopic moments", Journal of Sound and Vibration 131, pp. 417-430.

[9] K. E. Rouch, T. H. Mcmaines, R. W. Stephenson And M. F. Ermerick, 1989, "Modeling of complex rotor systems by combining rotor and substructure models". $4^{\text {th }}$ International ANSYS Conference and Exhibition, Part 2, 5.23-5.39.

[10] F. Dimentberg , 1961, "Flexural vibrations of rotating shafts". London: Butterworth.

[11] H. Black, 1974, "A linearized model using transfer matrix to study the forced whirling of centrifugal pumps rotor systems", Journal of Engineering for Industry.

[12] R. Sheldahl, P. Klimas, 1981, "Aerodynamic characteristics of seven symmetrical airfoil sections through 180-degree angle of attack for use in aerodynamic analysis of vertical axis wind turbines". Technical Report SAND80-2114, Sandia National Laboratories.

TABLE 3.

NATURAL FREQUENCY OF TURBINE SHAFT

\begin{tabular}{cccc}
\hline Mode & $\omega_{\mathrm{n}}(\mathrm{Hz})$ & Mode & $\omega_{\mathrm{n}}(\mathrm{Hz})$ \\
\hline 1 & 0.8 & 11 & 135.1 \\
2 & 4.6 & 12 & 155.8 \\
3 & 12.6 & 13 & 175.6 \\
4 & 23.9 & 14 & 193.9 \\
5 & 38.1 & 15 & 210.5 \\
6 & 54.7 & 16 & 224.9 \\
7 & 73.3 & 17 & 236.9 \\
8 & 93.3 & 18 & 246.5 \\
9 & 114.1 & 19 & 253.4 \\
10 & 135.1 & 20 & 257.7 \\
\hline \multicolumn{4}{c}{ TABLE 4. } \\
\multicolumn{4}{c}{ AvERAGE ERROR FOR ALL VARIATIONS } \\
\hline \multirow{2}{*}{0.8} & Average Error $(\%)$ & Average Error $(\%)$ \\
0.9 & X-direction & y-direction \\
1 & 18\% & \multicolumn{2}{c}{$18 \%$} \\
\hline
\end{tabular}




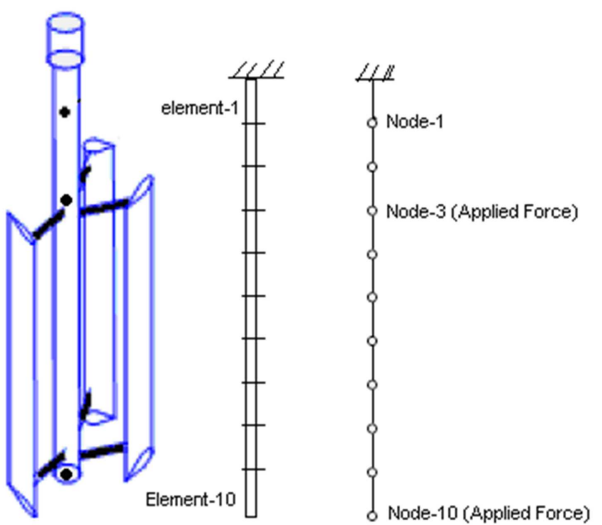

Fig. 1. Finite element model of vertical-axis turbine

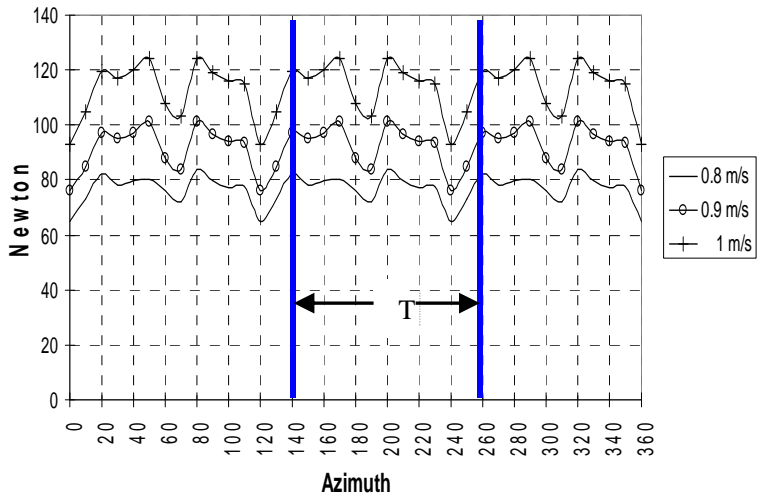

(a)

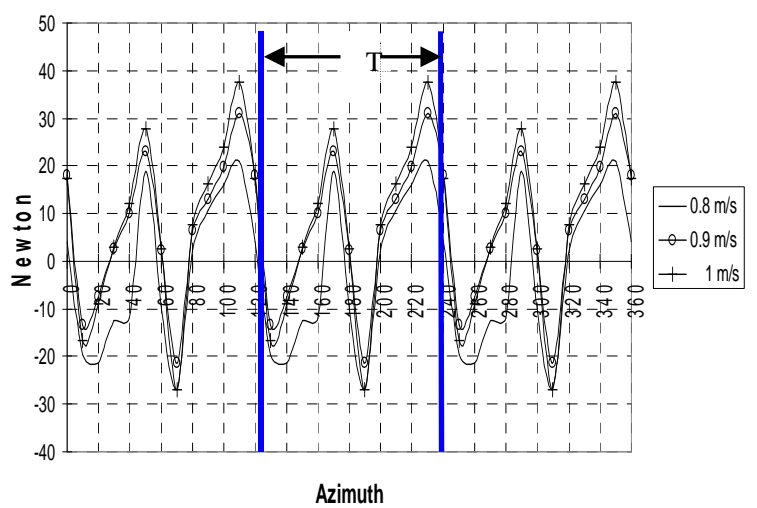

(b)

Fig. 3. Fluctuation pattern of the force at all variation, (a) x-direction, (b) y-direction

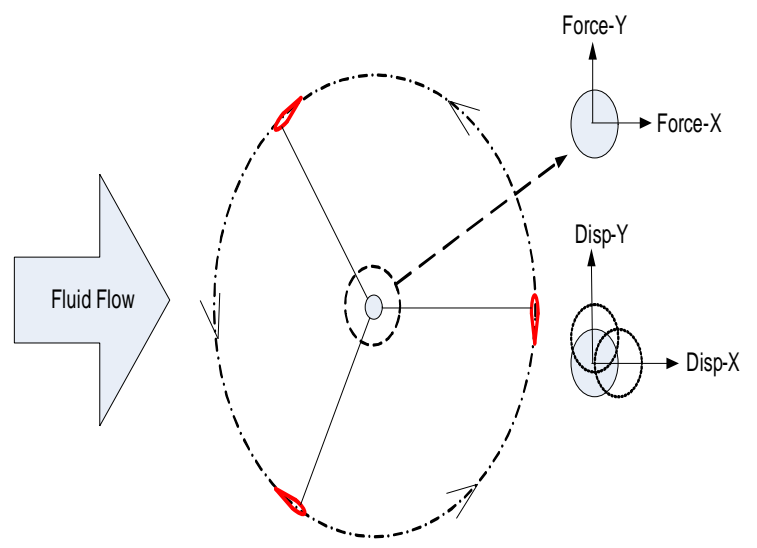

Fig. 2. Definition of the lateral direction of the force and the vibration on the main shaft of turbine

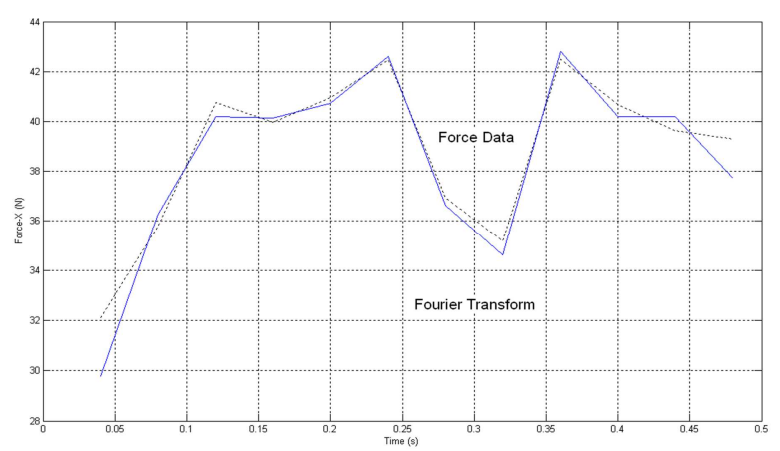

(a)

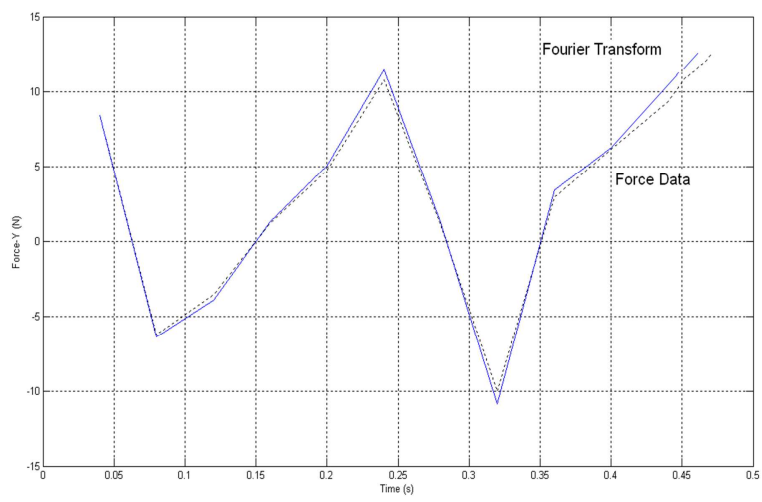

(b)

Fig. 4. The suitability of the force fluctuation pattern at Var-2 variation,(a) $\mathrm{x}$-direction (b) $\mathrm{y}$ - direction

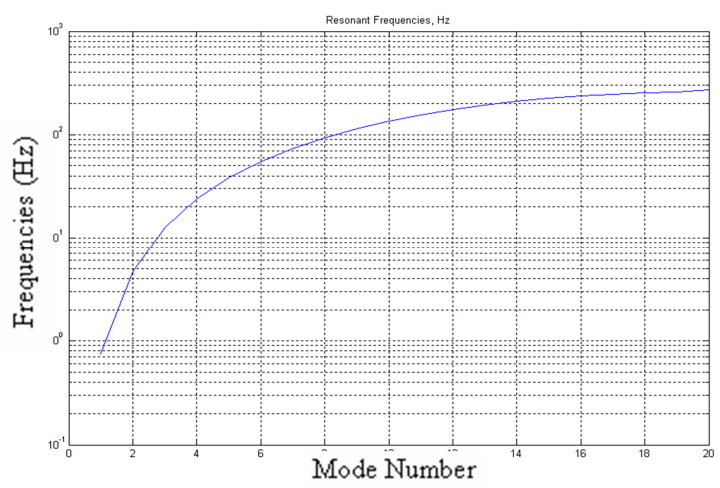

Fig. 5. Natural frequency of turbine shaft 


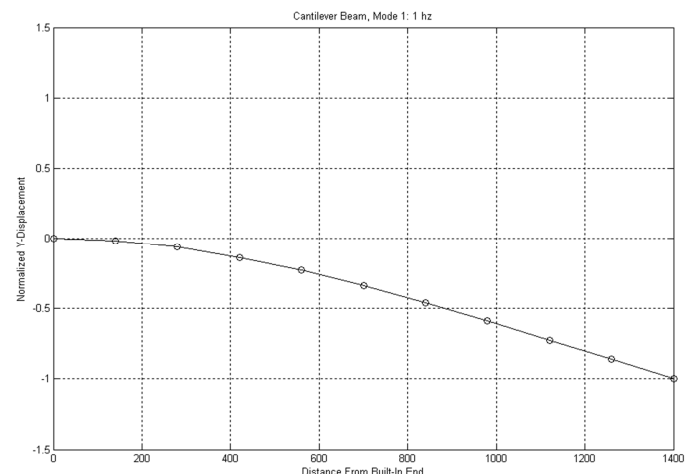

(a)

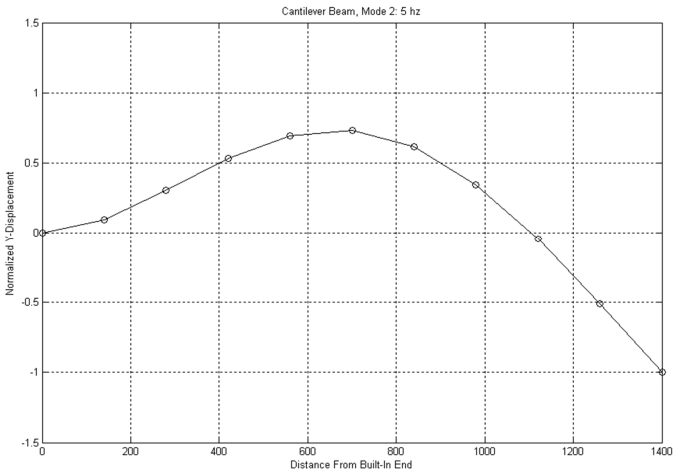

(b)

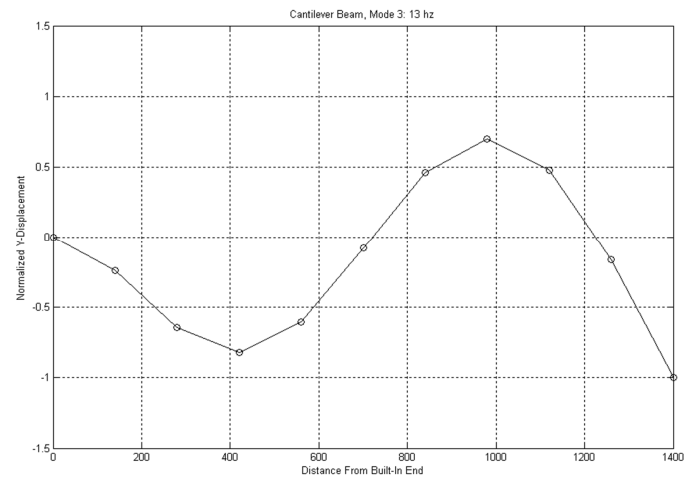

(c)

Fig. 6. First three mode shapes of main turbine shaft

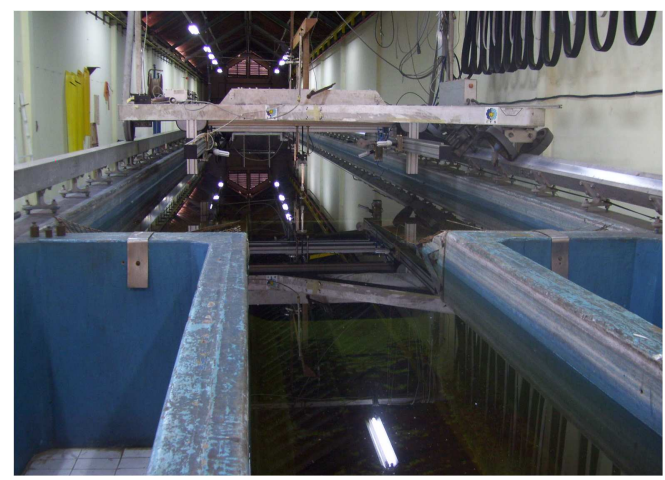

Fig. 7. Towing tank facility at FTK ITS

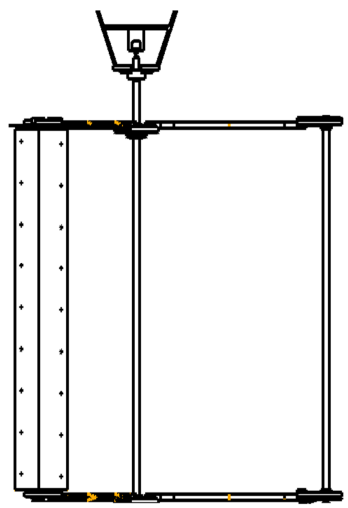

Fig. 8. Vertical-axis turbine withthree straight foils

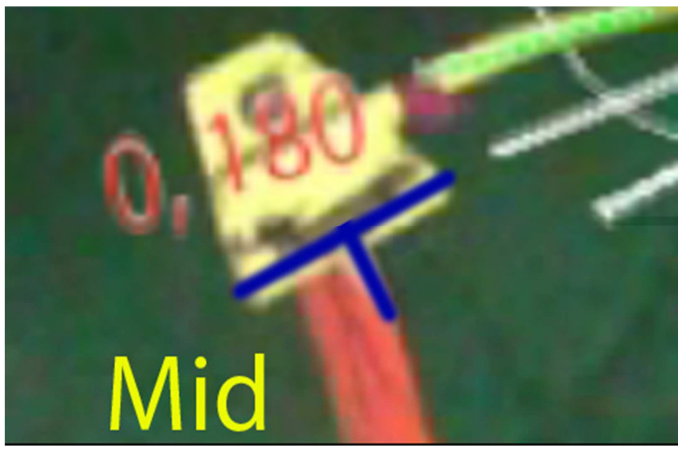

Fig. 9. Fixed-pitch position relative to arm

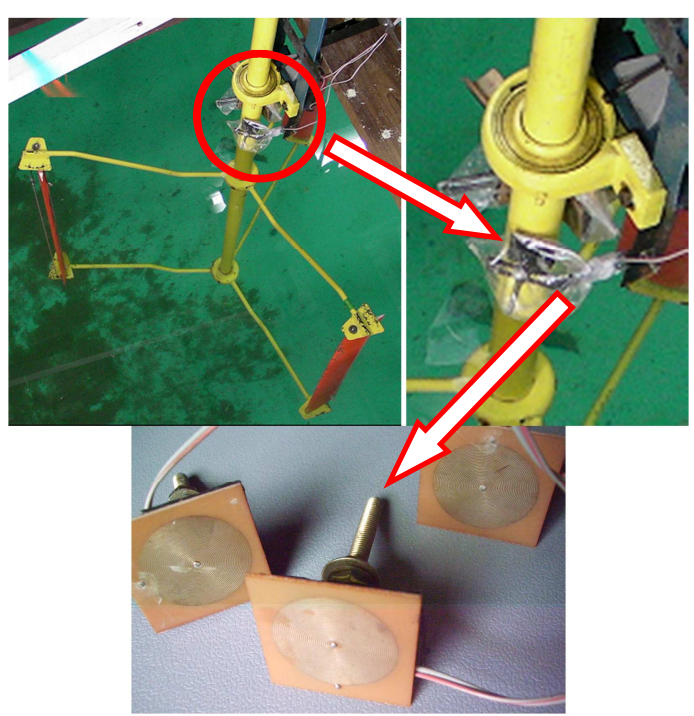

Fig. 10. Installation of Eddy current sensorsto the turbine shaft 


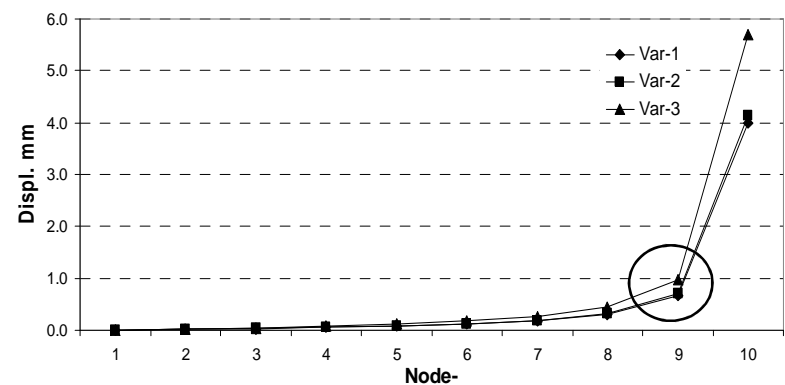

(a)

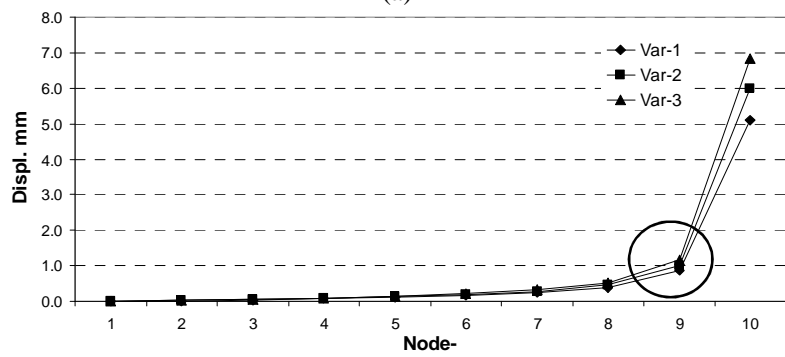

(b)

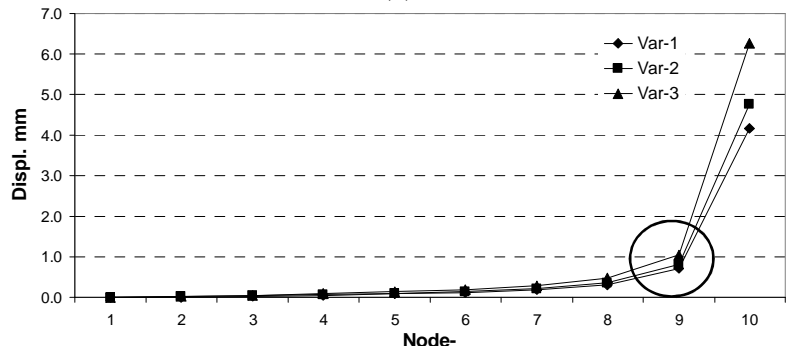

(c)

Fig. 11. Displacement in $\mathrm{x}$-direction at all nodes for all variations at (a) $\mathrm{t}_{\mathrm{i}=1}$, (b) $\mathrm{t}_{\mathrm{i}=10}$, (c) $\mathrm{t}_{\mathrm{i}=30}$

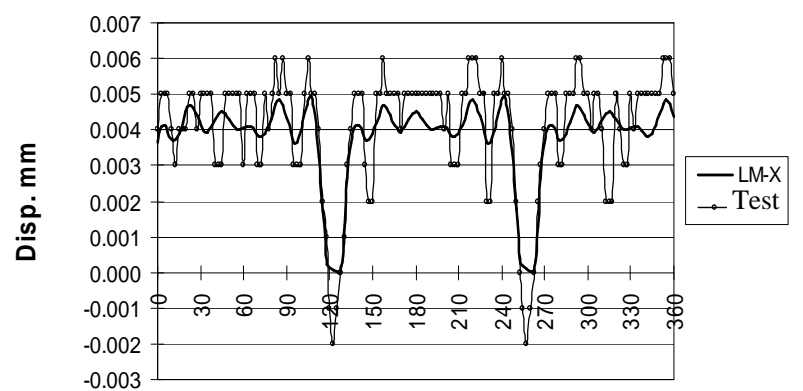

Azimuth

(a)

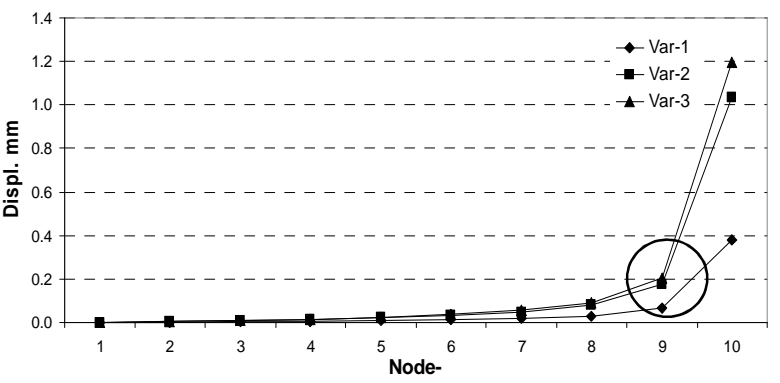

(a)

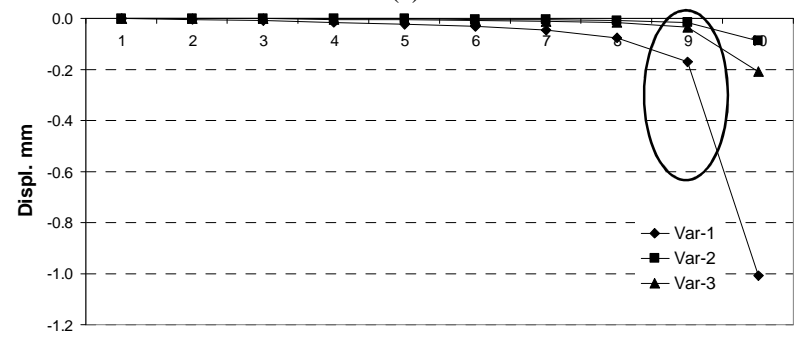

(b)

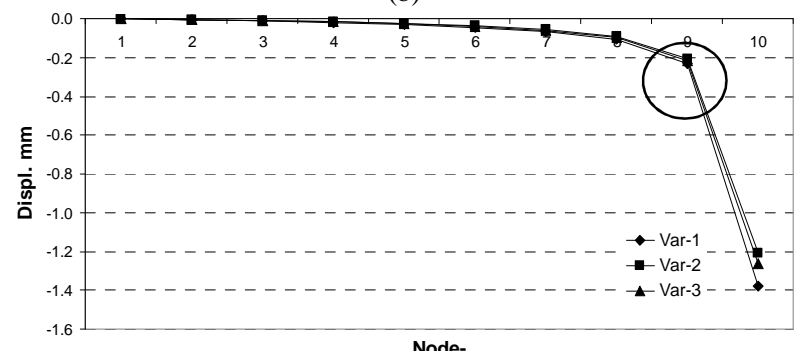

(c)

Fig. 12. Displacement in y-direction at all nodes for all variations at (a) $t_{i=1}$, (b) $t_{i=10}$, (c) $t_{i=30}$

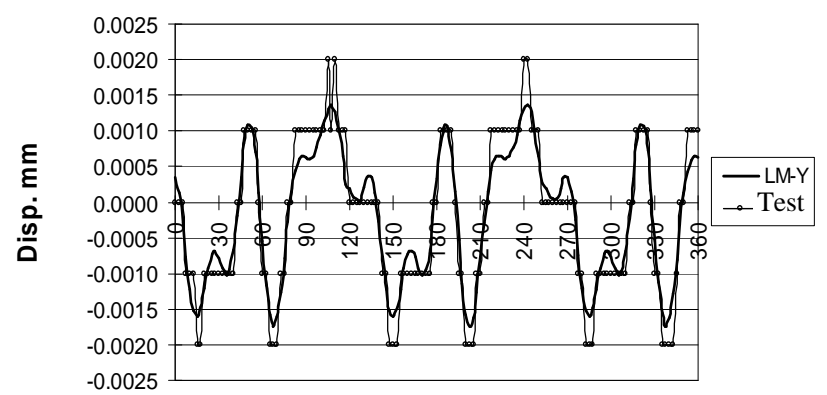

Azimuth

(b)

Fig. 13. Responses at node-1 at Var-1, (a) x-direction,(b) y-direction 


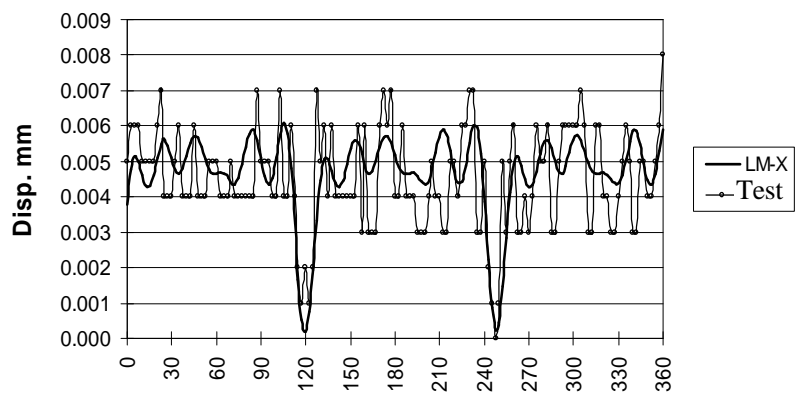

Azimuth

(a)

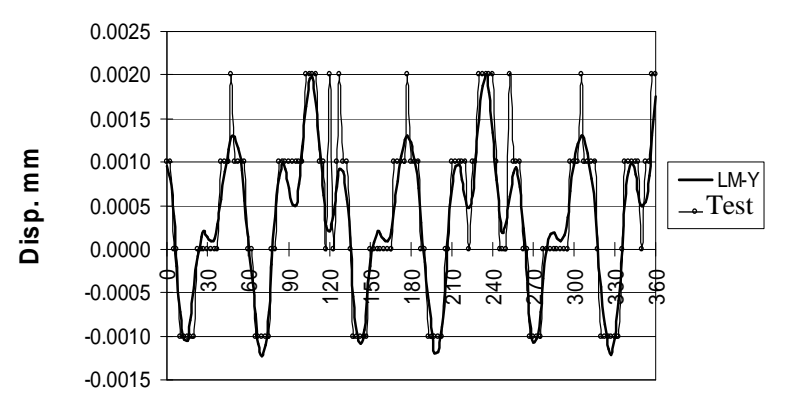

Azimuth

(b)

Fig. 14. Responses at node-1 at Var-2, (a) x-direction, (b) y-direction

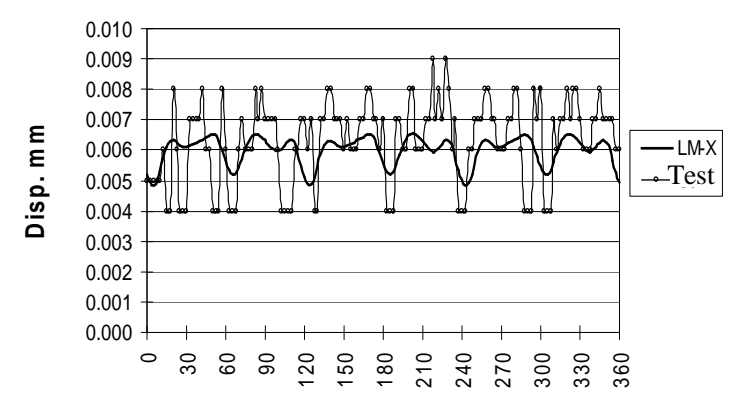

Azimuth

(a)

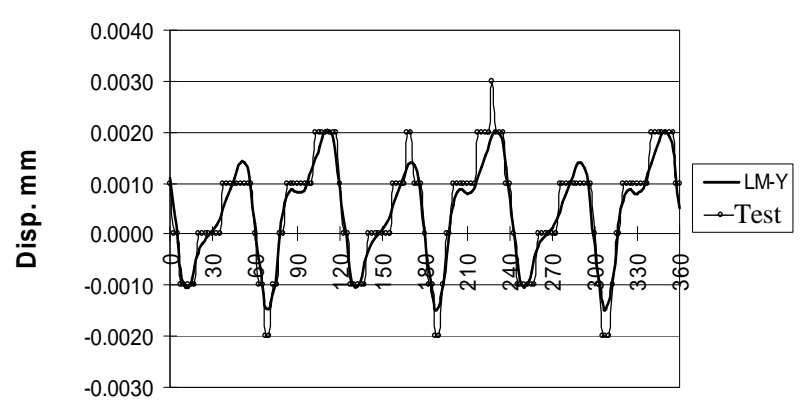

Azimuth

(b)

Fig. 15. Responses at node-1 at Var-3, (a) x-direction, (b) y-direction 
